\title{
FUNGOS MICORRÍZICOS ARBUSCULARES, BACTÉRIAS DIAZOTRÓFICAS E ADUBAÇÃO FOSFATADA EM MUDAS DE MAMOEIRO ${ }^{1}$
}

\author{
KÉSSIA BARRETO LIMA², MARCO ANTÔNIO MARTINS ${ }^{3}$, \\ MARTA SIMONE MENDONÇA FREITAS ${ }^{4}$, FÁBIO LOPES OLIVARES 5
}

RESUMO- Conduziu-se um experimento em casa de vegetação para avaliar o crescimento de mudas de mamoeiro inoculadas com fungos micorrízicos arbusculares (FMAs) e com bactérias diazotróficas, na ausência e presença de fósforo. $\mathrm{O}$ delineamento experimental foi o de blocos casualizados, em arranjo fatorial $4 \times 3 \times 2$, sendo os tratamentos compostos por: espécies de fungos micorrízicos arbusculares Glomus clarum, Gigaspora margarita, o inóculo misto Glomus clarum + Gigaspora margarita e o controle sem FMAs; as bactérias diazotróficas Stenotrophomonas maltophilia e Azospirillum sp. e o controle sem bactéria diazotrófica; duas doses de fósforo no solo, 0 e $25 \mathrm{mg} \mathrm{dm}^{-3}$, todos com quatro repetições. Aos 105 dias após a semeadura, as plantas foram coletadas e avaliadas quanto à altura, área foliar total, diâmetro do caule, matéria seca da parte aérea, da raiz e matéria seca total, porcentagem de colonização micorrízica e contagem de bactérias diazotróficas nas raízes. As inoculações com os FMAs proporcionam aumentos significativos no crescimento das mudas de mamoeiro, mesmo em condições de baixa disponibilidade de fósforo, independentemente da presença de bactéria diazotrófica. O fungo G. margarita e o inóculo misto G. margarita + G. clarum destacam-se como os mais promissores para a cultura do mamoeiro. A inoculação com bactérias diazotróficas, na ausência ou na presença de FMAs, não propiciou efeito estimulatório ou supressivo no crescimento das mudas de mamoeiro.

Termos para indexação: Carica papaya L., Gigaspora margarita, Glomus clarum, Stenotrophomonas maltophilia, Azospirillum sp.

\section{ARBUSCULAR MYCORRIHIZAL FUNGI, DIAZOTROPHIC BACTERIA AND PHOSPHATE FERTILIZATION ON PAPAYA SEEDLINGS}

\begin{abstract}
An experiment was carried out in a greenhouse to evaluate the growth of papaya seedlings inoculated with arbuscular mycorrhizal fungi (AMF) and diazotrophic bacteria, in the absence and presence of phosphorus. The experimental design was randomized blocks in a $4 \times 3 \times 2$ factorial scheme, treatments consisting of: species of mycorrhizal fungi Glomus clarum, Gigaspora margarita and mixed inoculum Glomus clarum + Gigaspora margarita and a control without AMF; diazotrophic bacteria Stenotrophomonas maltophilia and Azospirillum sp., and a control without diazotrophic bacteria, and two levels of phosphorus in the soil, 0 and $25 \mathrm{mg} \mathrm{dm}^{-3}$ with four replications. At 105 days after sowing, the plants were collected and evaluated for plant height, leaf area, stem diameter, dry matter of shoot, root and total dry matter, percentage of root colonization and enumeration of diazotrophs in roots. Inoculation with AMF provides significant increases in the growth of papaya seedlings, even under low phosphorus availability, regardless of the presence of diazotrophic bacteria. The fungus G. margarita and the mixed inoculum G. margarita + G. clarum stand out as the most promising to the cultivation of papaya. The inoculation with diazotrophic bacteria in the absence or presence of AMF did not provide suppressive or stimulatory effect on papaya growth.
\end{abstract}

Index terms: Carica papaya L., Gigaspora margarita, Glomus clarum, Stenotrophomonas maltophilia, Azospirillum sp.

\footnotetext{
1(Trabalho 198-10). Recebido em: 10-09-2010. Aceito para publicação em: 12-05-2011. Apoio Financeiro: CAPES e FAPERJ. ${ }^{2}$ Doutoranda em Produção Vegetal, Universidade Estadual do Norte Fluminense, Avenida Alberto Lamego, 2000, CEP- 28013-602, Campos dos Goytacazes-RJ, (22) 2739 7101, E-mail: kblima@hotmail.com

${ }^{3}$ DS. Professor, Universidade Estadual do Norte Fluminense, Avenida Alberto Lamego, 2000, CEP- 28013-602, Campos dos Goytacazes-RJ, E-mail: marco@uenf.br

${ }^{4}$ DS. Pesquisadora, Universidade Estadual do Norte Fluminense, Avenida Alberto Lamego, 2000, CEP- 28013-602, Campos dos Goytacazes-RJ, E-mail: msimone@uenf.br

${ }^{5}$ DS. Professor. Universidade Estadual do Norte Fluminense, Avenida Alberto Lamego, 2000, CEP- 28015-620, Campos dos Goytacazes-RJ, E-mail: fabioliv@uenf.br
} 


\section{INTRODUÇÃO}

O Brasil é o maior produtor mundial e o terceiro maior exportador de mamão (IBGE, 2007), com a produção estimada de aproximadamente 1,9 milhão de toneladas, em 36.700 ha de área cultivada (FAO, 2009). A maior parte da produção desta cultura está concentrada no norte do Estado do Espírito Santo e sul da Bahia, que apresentam solos de baixa fertilidade, principalmente no que se refere aos teores de fósforo $(\mathrm{P})$, levando os produtores a utilizarem altas doses de fertilizantes (OLIVEIRA, 2004).

Considerando-se a potencialidade que é conferida a esta cultura para o País e a necessidade crescente de fertilizantes fosfatados e nitrogenados para produções de mudas destinadas à renovação de pomares, existe claramente uma demanda por tecnologias alternativas que passem pela intensificação do uso de processos biológicos, com ganhos econômicos e ecológicos.

Existe uma interação funcional entre as bactérias endofíticas e os FMAs (PAULA et al., 1992). A transmissão das bactérias diazotróficas para as plantas pode ocorrer através de esporos de FMAs (BHOWMIK; SINGH, 2004; LI; STRZELCZYK, 2000; PAULA et al., 1991) ou pela colonização bacteriana em hifas extrarradiculares de FMAs (TOLJANDER et al., 2006). Além de fornecerem nutrientes para as bactérias que colonizam as superfícies ou o interior dos esporos, os FMAs conferem proteção contra dessecação, radiação, predação e salinidade (LEVY et al., 2009). Durante o processo de penetração das hifas infectivas, ocorre maior exsudação de nutrientes pela planta, acelerando o crescimento das bactérias (PAULA et al., 1991). De forma recíproca, as bactérias associadas aos esporos de FMAs podem promover o crescimento e rápida colonização pelo fungo, conforme sugerido por Bhowmik e Singh (2004).

A inoculação conjunta de bactérias diazotróficas e de fungos micorrízicos tem eficiência comprovada pela pesquisa em diferentes espécies, conferindo benefícios na nutrição, promoção de crescimento e proteção das mudas (BORGES et al., 2003). Existem vários relatos dos efeitos benéficos propiciados pela interação FMA-bactéria diazotrófica, em várias culturas, como milho (MIYAUCHI et al., 2008), trigo (SALA et al., 2007), arroz (RAIMAM et al., 2007), mandioca (BALOTA et al., 1999), batata-doce, canade-açúcar e sorgo (PAULA et al., 1991).

Por apresentar pouca ramificação de raízes e atingir pouca profundidade no solo, o sistema radicular do mamoeiro pode gerar deficiências nutricionais (SOUZA et al., 2000). Neste sentido, espera-se que a inoculação com FMAs e bactérias diazotróficas melhorem a nutrição e o desenvolvimento das mudas. Trindade et al. (2001b) demonstraram que cultivares de mamoeiro podem ser beneficiadas pela inoculação com Glomus clarum e Gigaspora margarita, reduzindo em até sete vezes a necessidade de aplicação de $\mathrm{P}$ no solo para se atingir a máxima produção de parte aérea. Entretanto, no que se refere à associação entre bactérias diazotróficas e mamoeiro, ainda existem poucos estudos. Desta forma, pesquisas que avaliem a interação entre bactérias diazotróficas e FMAs com a cultura do mamoeiro visando à promoção de crescimento, proteção vegetal e acúmulo de nutrientes ainda se fazem necessárias.

Diante deste contexto, este trabalho teve como objetivo avaliar a resposta de mudas do mamoeiro à inoculação com bactérias diazotróficas e FMAs, na ausência e na presença de fósforo.

\section{MATERIAL E MÉTODOS}

$\mathrm{O}$ experimento foi realizado em casa de vegetação, no Câmpus da Universidade Estadual do Norte Fluminense Darcy Ribeiro, localizado em Campos dos Goytacazes-RJ (Latitude $=21^{\circ} 19^{\prime} 23^{\prime \prime}$; Longitude $=41^{\circ} 10^{\prime} 40^{\prime \prime} \mathrm{W}$; Altitude $\left.=14 \mathrm{~m}\right)$, de 1604 a 31-07-2009.

$\mathrm{O}$ delineamento experimental adotado foi o de blocos casualizados, em arranjo fatorial 4 × 3 x 2 , sendo os tratamentos compostos por espécies de fungos micorrízicos arbusculares Glomus clarum (Nicolson e Schenck), Gigaspora margarita (Becker e Hall) e o inóculo misto Glomus clarum + Gigaspora margarita e o controle sem FMAs; as bactérias diazotróficas Stenotrophomonas maltophilia (NCBI J293470) e Azospirillum sp. TS 15 (NCBI AB114194) e o controle sem bactéria diazotrófica; e duas doses de fósforo no solo, $0 \mathrm{e} 25 \mathrm{mg} \mathrm{dm}^{-3}$, todos com quatro repetições. A unidade experimental foi composta por um vaso contendo $4 \mathrm{dm}^{3}$ de substrato, usando-se duas plantas por vaso.

O solo destinado ao preparo do inóculo de FMAs e para o experimento foi classificado como Cambissolo Háplico Tb Distrófico típico, coletado na profundidade de $0-20 \mathrm{~cm}$, peneirado, misturado com areia na proporção $1: 1\left(\mathrm{v} \mathrm{v}^{-1}\right)$ e esterilizado em autoclave à temperatura de $121^{\circ} \mathrm{C}$ por 1 hora. Após a autoclavagem, o substrato apresentou as seguintes características: $\mathrm{pH}$ (água), 5,9; M.O. 12,24 $\mathrm{g} \mathrm{dm}^{-3} ; \mathrm{P}$, $5,0 \mathrm{mg} \mathrm{dm}^{-3} ; \mathrm{S}, 7,0 \mathrm{mg} \mathrm{dm}^{-3} ; \mathrm{K}^{+}, 0,7 \mathrm{mmol}_{\mathrm{c}} \mathrm{dm}^{-3} ; \mathrm{Ca}^{2+}$, $13,0 \mathrm{mmol}_{\mathrm{c}} \mathrm{dm}^{-3} ; \mathrm{Mg}^{2+}, 12,1 \mathrm{mmol}_{\mathrm{c}} \mathrm{dm}^{-3} ; \mathrm{Al}^{3+}, 0,0$ $\mathrm{mmol}_{\mathrm{c}} \mathrm{dm}^{-3} ; \mathrm{H}+\mathrm{Al}, 12,5 \mathrm{mmol}_{\mathrm{c}} \mathrm{dm}^{-3} ; \mathrm{SB}, 26,3 \mathrm{mmol}_{\mathrm{c}}$ $\mathrm{dm}^{-3}$; CTC, 38,8 $\mathrm{mmol}_{\mathrm{c}} \mathrm{dm}^{-3} ; \mathrm{Fe}, 42,8 \mathrm{mg} \mathrm{dm}^{-3} ; \mathrm{Cu}^{\mathrm{c}}$, $0,50 \mathrm{mg} \mathrm{dm}^{-3} ; \mathrm{Zn}, 1,06 \mathrm{mg} \mathrm{dm}^{-3} ; \mathrm{Mn}, 59,3 \mathrm{mg} \mathrm{dm}^{-3}$ 
e B, 0,24 $\mathrm{mg} \mathrm{dm}^{-3}$. Ao substrato foram adicionados $\mathrm{P}$, utilizando-se como fonte de $\mathrm{KH}_{2} \mathrm{PO}_{4}$. Os teores de $\mathrm{K}$ foram aumentados para $100 \mathrm{mg} \mathrm{dm}^{-3}$, utilizando-se como fonte de $\mathrm{KH}_{2} \mathrm{PO}$ e $\mathrm{KCl}$. O substrato foi mantido por 42 dias incubado, devidamente umedecido.

Ao substrato destinado à multiplicação do inóculo fúngico em vasos de $3 \mathrm{dm}^{3}$, foram plantadas seis sementes de Brachiaria decumbens que tiveram a superfície desinfestada com solução de hipoclorito de sódio a $0,5 \%$ e lavadas com água esterilizada. Foram adicionados $50 \mathrm{~cm}^{3}$ de inóculo, constituindo uma mistura de solo contendo esporos, hifas e raízes colonizadas com o fungo de cada espécie a ser estudada: Glomus clarum e Gigaspora margarita. Os vasos foram mantidos em casa de vegetação, após o plantio, por um período de 90 dias.

As bactérias diazotróficas Stenotrophomonas maltophilia (NCBI AJ293470) e Azospirillum sp. TS 15 (NCBI AB114194) foram selecionadas como promissoras para promoção de crescimento em mudas de mamoeiro oriundas do Grupo Solo, isoladas a partir de raízes da cv. Golden (BODDEY et al., 2007) e da rizosfera da cv. Baixinho de Santa Amália (SANTOS, 2008), respectivamente. A produção do inoculante bacteriano foi realizada a partir da obtenção de colônias isoladas e crescidas em préinóculo contendo $5 \mathrm{~mL}$ de meio de cultivo líquido Dygs (DÖBEREINER et al., 1995) e mantidos sob agitação $\left(250 \mathrm{rpm}\right.$, por $\pm 24 \mathrm{~h}$ a $\left.30^{\circ} \mathrm{C}\right)$. O pré-inóculo obtido foi utilizado para produzir um volume maior de inoculante (1,5 L de meio líquido Dygs), sob as mesmas condições. Os inóculos foram padronizados em absorbância (leitura da densidade óptica em 560 nm) mediante a diluição e contagem em câmara de Neubauer, correspondendo a uma densidade de $10^{8}$ células por $\mathrm{mL}$.

Sementes de mamoeiro (Carica papaya L.) da cultivar Golden (Grupo Solo) foram fornecidas pela empresa Caliman Agrícola S/A. As sementes foram desinfestadas com hipoclorito de sódio $(0,5 \%)$, por 10 minutos, e colocadas para germinar em vasos de plástico contendo $4 \mathrm{dm}^{3}$ de substrato autoclavado, previamente adubados com P. No momento do plantio, foram inoculados os FMAs e as bactérias diazotróficas. Os substratos dos vasos destinados aos tratamentos com os FMAs foram inoculados com uma mistura de solo, esporos e raízes colonizadas com Glomus clarum ou Gigaspora margarita, deixandose o tratamento controle sem inoculação. Em cada vaso, foram adicionados $50 \mathrm{~cm}^{3}$ de inóculo. Para os vasos do tratamento contendo o inóculo misto, foi utilizado $25 \mathrm{~cm}^{3}$ de inóculo de cada espécie fúngica. A aplicação dos FMAs foi realizada em uma profundidade aproximada de $3 \mathrm{~cm}$ nos substratos dos vasos dos tratamentos correspondentes, procedendose a semeadura. Para os vasos dos tratamentos contendo bactérias diazotróficas, a inoculação consistiu na aplicação direta no substrato de $1 \mathrm{~mL}$ do inóculo $\left(10^{8}\right.$ células por $\left.\mathrm{mL}\right)$ ao redor de cada semente contida no vaso.

Quarenta e cinco dias após a germinação, foi realizado o desbaste das mudas, deixando-se duas plantas por vaso e foi reaplicado $1 \mathrm{~mL}$ de inóculo bacteriano diretamente ao redor de cada muda tratada com bactérias diazotróficas.

Aos 105 dias após a semeadura, foi realizada a avaliação do crescimento das mudas, sendo mensurados a altura, o diâmetro do caule (a 2 $\mathrm{cm}$ do solo) e a área foliar total (LI-6200, LI-COR) das mudas. As matérias secas das raízes, da parte aérea e a matéria seca total foram quantificadas após a secagem em estufa com circulação forçada de ar, a $75^{\circ} \mathrm{C}$ por 48 horas. A colonização de bactérias diazotróficas foi avaliada a partir de amostras radiculares, de acordo com Döbereiner et al. (1995), utilizando-se do meio semissólido NFb (OLIVEIRA et al., 2002) a partir de diluições seriadas de $10^{-2}$ até $10^{-6}$. A porcentagem de colonização micorrízica das raízes foi determinada após a coloração pelo método descrito por Grace e Stribley (1991), adaptado com $\mathrm{KOH}(5 \%)$ a $80^{\circ} \mathrm{C}$, por 10 minutos, e $\mathrm{H}_{2} \mathrm{O}_{2}$ alcalina $5 \%$, por 7 minutos. Os segmentos de raízes foram levados ao microscópio óptico para a observação da presença de estruturas de FMAs.

Os dados experimentais obtidos foram submetidos à análise de variância, e a comparação entre as médias dos tratamentos foi feita pelo teste de Tukey, a 5\% de probabilidade.

\section{RESULTADOS E DISCUSSÃO}

A altura das mudas de mamoeiro foi influenciada pela inoculação com os FMAs e pelas doses de P no substrato (Tabela 1). No entanto, não foi influenciada pela inoculação com as bactérias diazotróficas. A inoculação com todos os FMAs proporcionou maior crescimento em altura, comparativamente ao controle sem FMAs, em ambas as doses de $\mathrm{P}\left(0\right.$ e $\left.25 \mathrm{mg} \mathrm{dm}^{-3}\right)$. Na ausência da adubação fosfatada, a altura das mudas foi maior nos tratamentos inoculados com inóculo misto e G. margarita. Os resultados obtidos no presente trabalho demonstram a eficiência destes fungos em promover o crescimento das plantas de mamoeiro, mesmo em condições de baixa disponibilidade de P no solo.

Trindade et al. (2001a) observaram que a inoculação com FMAs aumentou significativamente a 
altura das mudas e o número de folhas da maioria dos genótipos de mamoeiro do Grupo Solo e Formosa. O valor máximo de altura das mudas obtido por estes autores foi correspondente a $12 \mathrm{~cm}$, aos 41 dias após o transplantio, quando inoculadas com G. margarita, aplicando-se $20 \mathrm{mg} \mathrm{dm}^{-3}$ de P. Utilizando esterco na composição do substrato para produção de mudas de mamoeiro da cv. Sunrise Solo inoculadas com G. etunicatum, Trindade et al. (2000) observaram que as médias das alturas das mudas variaram de 7 a 19,5 cm aos 45 dias após o transplantio.

Trabalhando com mudas de mamoeiro 'Formosa', aos 140 dias após a semeadura, Mendonça et al. (2006) conseguiram obter médias de alturas de plantas que variaram entre $15 \mathrm{a} 18 \mathrm{~cm}$, adicionandose a dose de $10 \mathrm{~kg} \mathrm{~m}^{-3}$ de superfosfato simples com a adição de $20 \%$ ou $40 \%$ de composto orgânico. Da mesma forma, Medeiros et al. (2009) obtiveram o valor de altura máxima de $22,2 \mathrm{~cm}$, na produção de mudas de mamoeiro, após 150 dias, utilizando-se da dose de $10 \mathrm{~kg} \mathrm{~m}^{-3}$ de superfosfato simples, sob diferentes proporções de matéria orgânica.

A altura média ideal para que as mudas de mamoeiro sejam levadas ao campo é de 15 a $20 \mathrm{~cm}$ (CHAVES et al., 2000), que pode ser obtido num período entre 45 a 60 dias após a germinação (LIMA et al., 2007). No presente trabalho, foram obtidas mudas de mamoeiro com $15 \mathrm{~cm}$ de altura aos 30 dias após a germinação, quando inoculadas com $G$. margarita, tanto na presença quanto na ausência de bactéria diazotrófica, utilizando-se da dose $25 \mathrm{mg}$ $\mathrm{dm}^{-3}$ de P. Isto demonstra a capacidade dos FMAs em potencializar a produção de mudas de qualidade, reduzindo o período de produção das mudas.

A associação simbiótica mutualística formada entre os FMAs e as raízes de fruteiras é de grande importância para as plantas que passam por fase de viveiro, pois antecipa o tempo de transplantio para o campo, estimulando o crescimento da muda e, consequentemente, reduzindo o seu tempo de aclimatação, o que aumenta a produtividade, a rotatividade na ocupação da infraestrutura e a eficiência de utilização da mão de obra especializada (SILVEIRA et al., 2003).

Em relação ao diâmetro do caule, à área foliar total e à matéria seca da parte aérea e da raiz das mudas de mamoeiro, foi possível observar que as médias das mudas micorrizadas foram significativamente maiores, quando comparadas às não inoculadas com FMA, independentemente da presença de bactérias diazotróficas e das doses de $\mathrm{P}$ no solo (Tabela 2). O diâmetro das mudas inoculadas com G. clarum e G. margarita, de forma combinada ou isolada, foi três vezes maior que o das mudas não inoculadas com FMA (Tabela 2). Ao avaliarem o efeito do desenvolvimento de mudas de mamoeiro inoculadas com G. margarita e G. etunicatum, em condições de campo sob diferentes formas de adubação, Trindade et al. (2003) observaram que as mudas micorrizadas por G. etunicatum apresentaram maior diâmetro do caule nos primeiros meses de crescimento da planta após o plantio.

Apesar de a inoculação com os FMAs proporcionar aumento na área foliar total das mudas de mamoeiro, não diferindo estatisticamente entre si (Tabela 2), o inóculo misto proporcionou o maior valor com incremento de $1.903 \%$ em comparação com as mudas não micorrizadas. Aumentos na área foliar, proporcionados pela inoculação com FMAs, foram obtidos em mudas de aceroleira (COSTA et al., 2001), maracujazeiro-doce (ANJOS et al., 2005, SILVA et al., 2004) e maracujazeiro-amarelo (CAVALCANTE, 2002).

As mudas de mamoeiro inoculadas com FMAs apresentaram valores significativos, em relação ao acúmulo de matéria seca de raízes, parte aérea e matéria seca total, sendo maiores que o controle não micorrizado (Tabela 2). Dentre os tratamentos fúngicos, o inóculo misto destacou-se, proporcionando os maiores incrementos no que se refere às matérias secas da raiz, parte aérea e matéria seca total.

$\mathrm{O}$ mamoeiro apresenta elevada resposta à micorrização (MINHONI; AULER, 2003; TRINDADE et al., 2001a; MARTINS et al., 2000). Com o objetivo de avaliar a eficiência simbiótica e o potencial de inoculação de mudas de mamoeiro com FMAs em solo não fumigado, Trindade et al. (2000) observaram que o benefício da inoculação com $G$. clarum e G. margarita situou-se em $67,7 \%$ e $73,1 \%$, respectivamente, sobre a massa da matéria seca da parte aérea das mudas, mesmo na presença de outros competidores. Isto demonstrou a eficiência dos FMAs na produção de mudas desta cultura.

Dentre os tratamentos inoculados com FMAs, a espécie G. clarum foi a que proporcionou os menores resultados em comparação aos demais fungos, no que se refere ao acúmulo de matéria seca das mudas de mamoeiro. O aumento significativo na produção de matéria seca através da inoculação com $G$. clarum foi demonstrado por Martins et al. (2000) em mamoeiro. Entretanto, esses mesmos autores observaram que, na dose $50 \mathrm{mg} \mathrm{dm}^{-3} \mathrm{de} \mathrm{P}$, não houve aumento significativo na produção de matéria seca e no conteúdo de $\mathrm{P}$ da parte aérea das mudas de mamoeiro.

Não houve efeito significativo da inoculação isolada das bactérias diazotróficas ou em conjunto com os FMAs. Também não foi observado efeito supressivo no desenvolvimento das plantas de ma- 
moeiro, quando inoculado os FMAs. Em condições de baixa disponibilidade de $\mathrm{P}$, a inoculação conjunta pode gerar competição entre os microrganismos, prejudicando o desenvolvimento das plantas. Diversos trabalhos demonstraram que a inoculação conjunta de bactérias diazotróficas e FMAs variam em eficiência na promoção do crescimento de mudas de diferentes culturas, como em arroz (RAIMAM et al., 2007), trigo (SALA et al., 2007) e mandioca (BALOTA et al., 1999).

Os benefícios da interação FMA e bactéria diazotrófica podem ser atribuídos ao incremento na absorção de $\mathrm{P}$ pelas plantas micorrizadas, propiciando melhores condições para o estabelecimento da associação com bactérias diazotróficas e para o funcionamento da nitrogenase (ARTURSSON et al., 2006). Acréscimos de $25 \%$ no acúmulo de matéria seca da parte aérea das mudas de mamoeiro 'Formosa' foram obtidos pela inoculação isolada da bactéria diazotrófica do gênero Stenotrophomonas, quando se utilizou o substrato Plantmax ${ }^{\circledR}$ (BODDEY et al., 2007). É possível que a dose de $P$ testada no presente trabalho ( $\left.25 \mathrm{mg} \mathrm{dm}^{-3}\right)$ tenha sido menor que a necessária para manter o funcionamento da nitrogenase que requer alto custo energético. Mendonça et al. (2009) observaram dentre as diferentes combinações de Plantmax ${ }^{\circledR}$ avaliadas, que o substrato Plantmax ${ }^{\circledR}$ + areia + solo, na proporção de 1:1:3 (contendo 49,8 $\mathrm{mg} \mathrm{dm}{ }^{-3}$ de P no substrato), foi o que promoveu os melhores resultados na produção das mudas do mamoeiro. Em adição, estes autores afirmam que este substrato apresentou valores mais expressivos em relação à maior parte dos nutrientes, principalmente em relação aos macronutrientes de grande importância para a cultura do mamoeiro como $\mathrm{K}, \mathrm{Mg}$ e, em especial, $\mathrm{P}$ e Ca. Estudando tipos de substratos na produção de mudas de mamoeiro, Negreiros et al. (2005) relacionaram o melhor substrato com o maior teor de fósforo presente no mesmo. Isso mostra a importância do suprimento deste nutriente no solo para o desenvolvimento das mudas de mamoeiro.

As porcentagens da colonização micorrízica evidenciam o efeito dos FMAs, independentemente da ausência ou da presença de bactéria diazotrófica e da adição de $\mathrm{P}$ ao solo (Figura 1). As médias obtidas pelos inóculos misto e G. clarum foram estatisticamente superiores aos tratamentos inoculados com $G$. margarita e ao controle (sem fungo), correspondendo a 97,1 e $95,8 \%$, respectivamente. Apesar disso, a taxa de colonização micorrízica radicular do $G$. margarita, assim como dos demais FMAs, foi de $90,8 \%$, sendo maior que as obtidas por Trindade et al. (2000), Trindade et al. (2001a), Trindade et al. (2001b). Este elevado potencial de colonização radicular nas mudas de mamoeiro pode explicar os resultados significativos obtidos nas características avaliadas referentes à promoção de crescimento.

Embora no presente trabalho tenha ocorrido um aumento significativo no número das bactérias diazotróficas S. maltophilia e Azospirillum sp. nas raízes do mamoeiro em relação ao tratamentocontrole, não ocorreu um aumento significativo no crescimento das mudas, independentemente da dose de P avaliada e da presença dos FMAs (Figura 2). Os benefícios da interação entre FMA e bactéria diazotrófica no crescimento vegetal podem ser atribuídos ao aumento na absorção de P pelas micorrizas, propiciando melhores condições para o estabelecimento da associação com bactérias diazotróficas e para o funcionamento da nitrogenase (ARTURSSON et al., 2006). Dessa forma, é necessário enfatizar a importância de novos estudos que envolvam a fixação biológica de nitrogênio na cultura do mamoeiro, buscando a utilização de espécies promissoras quanto à promoção de crescimento vegetal, de acordo com os genótipos avaliados.

TABELA 1 - Altura das mudas (cm) de mamoeiro da cultivar Golden em função da inoculação de fungo micorrízico arbuscular (FMA) e das doses de P no substrato, com os incrementos relativos (IR\%), aos 105 dias após a semeadura.

\begin{tabular}{|c|c|c|c|c|c|c|c|c|}
\hline \multirow{2}{*}{ Doses de $\mathrm{P}$} & \multicolumn{8}{|c|}{ FMA } \\
\hline & Sem FMA & G. margarita & $\mathrm{IR}_{\mathrm{F}} \%$ & G. clarum & $\mathrm{IR}_{\mathrm{F}} \%$ & Inóculo Misto & $\mathrm{IR}_{\mathrm{F}} \%$ & Médias \\
\hline $0 \mathrm{mg} \mathrm{dm}^{-3}$ & $5,4 \mathrm{cB}$ & $28,0 \mathrm{aA}$ & 419 & $25,3 \mathrm{bB}$ & 369 & $29,3 \mathrm{aA}$ & 443 & 21,9 \\
\hline $25 \mathrm{mg} \mathrm{dm}^{-3}$ & $9,9 \mathrm{bA}$ & $29,5 \mathrm{aA}$ & 198 & $28,1 \mathrm{aA}$ & 184 & $29,5 \mathrm{aA}$ & 198 & 24,3 \\
\hline $\mathrm{IR}_{\mathrm{p}} \%$ & $83 \%$ & $5 \%$ & - & $11 \%$ & - & $1 \%$ & - & \\
\hline Médias & 7,7 & 28,8 & & 26,7 & & 29,4 & & 23,1 \\
\hline CV (\%) & & & & 10,3 & & & & \\
\hline
\end{tabular}

Médias seguidas da mesma letra, minúscula na linha e maiúscula na coluna, não diferem entre si, pelo teste de Tukey, a 5\% de probabilidade. Incremento relativo à inoculação com $\mathrm{FMA}\left[\mathrm{IR}_{\mathrm{F}} \%=100(\mathrm{x}-\mathrm{y}) / \mathrm{y}\right.$, sendo $\mathrm{x}$ : altura da planta inoculada, e y: altura da planta- controle (não inoculada)]; Incremento relativo à presença de $\mathrm{P}$ no substrato $\left[\left(\mathrm{IR}_{\mathrm{P}} \%=100(\mathrm{x}-\mathrm{y}) / \mathrm{y}\right.\right.$, sendo $\mathrm{x}$ : com $\mathrm{P}$, e y: sem $\left.\left.\mathrm{P}\right)\right]$. 
TABELA 2 - Diâmetro do caule, área foliar e matéria seca de raiz e da parte aérea de mudas de mamoeiro da cultivar Golden, em função da inoculação com fungo micorrízico arbuscular (FMA), aos 105 dias após a semeadura.

\begin{tabular}{|c|c|c|c|c|c|c|c|c|c|c|}
\hline \multirow{2}{*}{ FMA } & \multirow{2}{*}{$\begin{array}{l}\text { Diâmetro do } \\
\text { caule (mm) }\end{array}$} & \multirow[b]{2}{*}{$\mathrm{IR}_{\mathrm{F}} \%$} & \multirow{2}{*}{$\begin{array}{r}\text { Área foliar } \\
\text { total }\left(\mathrm{cm}^{2}\right)\end{array}$} & \multirow[b]{2}{*}{$I_{F} \%$} & \multicolumn{6}{|c|}{ Matéria seca (g planta $\left.{ }^{-1}\right)$} \\
\hline & & & & & Raiz & $I_{\mathrm{F}} \%$ & Parte aére & $I_{\mathrm{F}} \%$ & Total & $I_{\mathrm{F}} \%$ \\
\hline Sem FMA & $1,95 \mathrm{c}$ & - & $13,8 \mathrm{~b}$ & - & $0,07 \mathrm{c}$ & - & $0,11 \mathrm{c}$ & - & $0,18 \mathrm{~d}$ & - \\
\hline G. margarita & $9,28 \mathrm{a}$ & 376 & $249,51 \mathrm{a}$ & 1708 & $1,09 \mathrm{a}$ & 1457 & $2,40 \mathrm{a}$ & 2082 & $3,49 \mathrm{~b}$ & 1839 \\
\hline G. clarum & $7,85 \mathrm{~b}$ & 303 & $243,61 \mathrm{a}$ & 1665 & $0,78 \mathrm{~b}$ & 1014 & $2,11 \mathrm{~b}$ & 1818 & $2,90 \mathrm{c}$ & 1511 \\
\hline Inóculo misto & $9,31 \mathrm{a}$ & 377 & $276,40 \mathrm{a}$ & 1903 & $1,24 \mathrm{a}$ & 1671 & $2,65 \mathrm{a}$ & 2309 & $3,89 \mathrm{a}$ & 2061 \\
\hline Médias & 7,10 & & 195,85 & & 0,80 & & 1,82 & & 2,61 & \\
\hline $\mathrm{CV}(\%)$ & 13,5 & & 34,0 & & 26,8 & & 18,6 & & 19,5 & \\
\hline
\end{tabular}

Médias seguidas pela mesma letra na coluna não diferem entre si, pelo teste Tukey, a 5\% de probabilidade; Incremento relativo das matérias fresca e seca $\left[\left(\operatorname{IR}_{\mathrm{F}} \%\right)=100(\mathrm{x}-\mathrm{y}) / \mathrm{y}\right.$, sendo $\mathrm{x}$ : matéria (fresca ou seca) da planta inoculada, e y: matéria (fresca ou seca) da planta não inoculada].

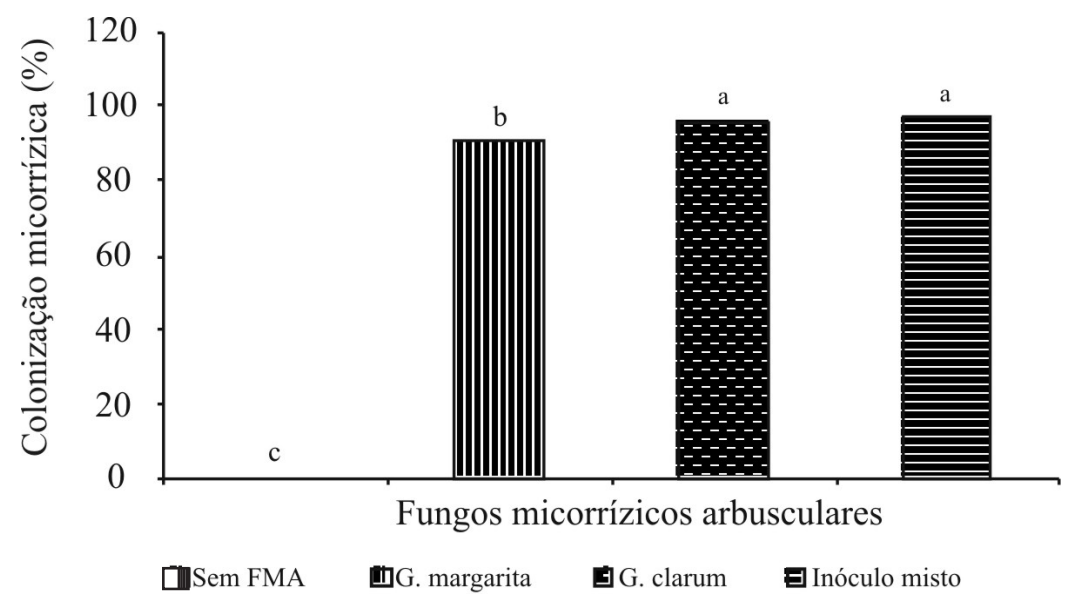

FIGURA 1 - Colonização micorrízica em raízes de mudas de mamoeiro da cultivar Golden, aos 105 após a semeadura. Médias seguidas pela mesma letra não diferem entre si, pelo teste de Tukey, à significância de $5 \%$. CV=9,2\%.

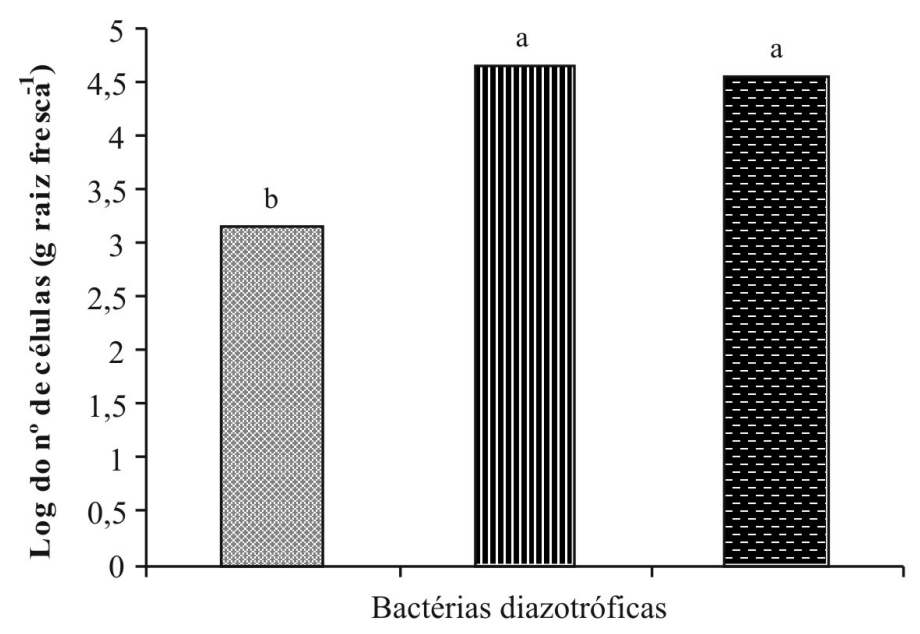
圈Sem bactéria
ШS. maltophilia
- Azospirillum sp.

FIGURA 2 - Número de bactérias fixadoras de nitrogênio em mudas de mamoeiro da cultivar Golden, aos 105 dias após a semeadura. Valores acompanhados da mesma letra não diferem entre si $(\mathrm{p}>0,05) . \mathrm{CV}=22,4 \%$. 


\section{CONCLUSÕES}

1 - As mudas de mamoeiro, inoculadas com os fungos micorrízicos arbusculares, crescem e desenvolvem-se melhor que as mudas não inoculadas, independentemente da presença de bactérias diazotróficas e de fósforo no solo.

2 - O crescimento das mudas de mamoeiro é incrementado pela inoculação com o fungo micorrízico Gigaspora margarita e pelo inóculo misto Gigaspora margarita e Glomus clarum.

3 - O crescimento das mudas de mamoeiro não é estimulado ou suprimido pela inoculação com as bactérias diazotróficas, na ausência ou presença de fungos micorrízicos arbusculares.

\section{REFERÊNCIAS}

ANJOS, E.C.T. dos, CAVALCANTE, U.M.T.; SANTOS, V.F;, MAIA, L.C. Produção de mudas de maracujazeiro doce micorrizadas em solo desinfestado e adubado com fósforo. Pesquisa Agropecuária Brasileira, Brasília, v.40, p.345$351,2005$.

ARTURSSON, V.; FINLAY, R. D.; JANSSON, J. K. Interactions between arbuscular mycorrhizal fungi and bacteria and their potential for stimulating plant growth. Environmental Microbiology, London, v.8, p.1-10, 2006.

BALOTA, E.L.; LOPES, E.S.; HUNGRIA, M.; DOBEREINER, J. Ocorrência de bactérias diazotróficas e fungos micorrízicos arbusculares na cultura da mandioca. Pesquisa Agropecuária Brasileira, Brasília, v. 34, p. 1265-1276, 1999.

BHOWMIK, S. N.; SINGH, C. S. Mass multiplication of AM inoculum; effect of plant growthpromoting rhizobacteria and yeast in rapid culturing of Glomus mosseae. Current Science, Bangalore, v.86, p.705-709, 2004.

BODDEY, L.H.; BARRETO, L.K.; ANDRADE, V.S.; GOMES, R.A.; OLIVARES, F.L. Avaliação da colonização de bactérias diazotróficas e seus efeitos na promoção de crescimento na cultura do mamoeiro (Carica papaya L.). In: REUNIÃO DE PESQUISA DO FRUTIMAMÃO, 2., 2007, Campos dos Goytacazes. Anais... v.1, p. 50-52. (Boletim Técnico)
BORGES, A. L. Cultivo orgânico de fruteiras tropicais: manejo do solo e da cultura. Cruz das Alvas: EMBRAPA, 2003. p.12. (Circular Técnica, 64)

CAVALCANTE, U.M.T.; MAIA, L.C.; COSTA, C.M.C.; CAVALCANTE, A.T.; SANTOS, V.F. Efeito de fungos micorrízicos arbusculares, da adubação fosfatada e da esterilização do solo no crescimento de mudas de maracujazeiro-amarelo. Revista Brasileira de Ciência do Solo, Viçosa, MG, v. 26, p.1099-1106, 2002.

CHAVES, J.C.M.; CAVALCANTI JUNIOR, A.T.; CORREIA, D.; SOUZA, F.X. de; ARAÚJO, C.A.T. Normas de produção de mudas. Documentos Embrapa Agroindústria Tropical, Fortaleza, v. 41, p. 37, 2000.

COSTA, C.M.C.; MAIA, L.C.; CAVALCANTE, U.M.T. Influência de fungos micorrízicos arbusculares sobre o crescimento de dois genótipos de aceroleira (Malpighia emarginata D.C.). Pesquisa Agropecuária Brasileira, Brasília, v.36, p. 893901, 2001

DÖBEREINER, J.; BALDANI, V.L.D.; BALDANI, J.I. Como isolar e identificar bactérias diazotróficas de plantas não leguminosas. Seropédica: Embrapa Agrobiologia, 1995. p.66.

FAO. Papaya production and harvested area. Disponível em: $<$ http://faostat.fao.org $>$. Acesso em: 24 maio 2009.

GRACE, C.; TRIBLEY, D.P. A safer procedure for routine staining of vesicular-arbuscular mycorrhizal fungi. Mycological Research, London, v. 95, p. 1160-1162, 1991

IBGE. Produção agrícola municipal: quantidade e valor da produção, área plantada e colhida. Disponível em: $<$ http:/www.sidra.ibge.gov.br $>$. Acesso em: 14 dez. 2007.

LEVY, A.; MAYO, M.J.; CHANG, B. J.; ABBOTT, L. K.; INGLIS, T. J. J. Association between Burkholderia species and arbuscular mycorrhizal fungus spores in soil. Soil Biology and Biochemistry, Oxford, v.41, p.1757-1759, 2009.

LI, C.Y.; STRZELCZYK, E. Belowground microbial process underpin forest productivity. Phyton, Buenos Aires, v.40, p.129-134, 2000. 
LIMA, J. F.; PEIXOTO, C. P.; LEDO, C. A. das. Índices fisiológicos e crescimento inicial de mamoeiro (Carica papaya L.) em casa de vegetação. Ciência e Agrotecnologia, Lavras, v. 31, p. 1358-1363, 2007.

MARTINS, M. A.; GONÇALVES, G. F.; SOARES, A. C. F. Efeito de fungos micorrízicos arbusculares associados a compostos fenólicos, no crescimento de mudas de mamoeiro. Pesquisa Agropecuária Brasileira, Brasília, v. 7, p. 1465-1471, 2000.

MEDEIROS, E. V.; CARVALHO NETO, R. A.; MENDONÇA, V.; JESUS, D. D.; MELO, J. K. H.; ARAÚJO, F. A. R. de. Superfosfato triplo e substrato alternativo na produção de mudas de mamoeiro. Bioscience Journal, Uberlândia, v. 25, p. 55-62, 2009.

MENDONÇA, V.; ABREU, N. A. A. de; GURGEL, R. L. da S.; FERREIRA, E. A.; ORBES, M. Y.; TOSTA, M. da S. Doses de nitrogênio e superfosfato simples no crescimento de mudas de mamoeiro 'Formosa'. Ciência e Agrotecnologia, Lavras, v. 30, p. 1065-1070, 2006.

MENDONÇA, V.; RAMOS, J. D.; ABREU, N. A. A. de; TEIXEIRA, G. A.; SOUZA, H. A. de; GURGEL, R. L. DA S.; ORBES, M. Y. Adubação nitrogenada em cobertura e substratos na produção de mudas de mamoeiro 'Formosa'. Ciência e Agrotecnologia, Lavras, v. 33, p. 668-675, 2009.

MINHONI, M. T. A.; AULER, P. A. M. Efeito do fósforo, fumigação do substrato e fungo micorrízico arbuscular sobre o crescimento de plantas de mamoeiro. Revista Brasileira de Ciência do Solo, Viçosa, MG, v.27, p. 841-847, 2003.

MIYAUCHI, M.Y.H.; LIMA, D.S.; NOGUEIRA, M.A.; LOVATO, G.M.; MURATE, L.S.; CRUZ, M.F.; FERREIRA, J.M.; ZANGARO, W.; ANDRADE, G. Interactions between diazotrophic bacteria and mycorrhizal fungus in maize genotypes. Scientia Agrícola, Piracicaba, v. 65, p. 525-531, 2008.

NEGREIROS, J. R. da S.; BRAGA, L. R.; ÁLVARES, V. DE S.; BRUCKNER, C. H. Diferentes substratos na formação de mudas de mamoeiro do grupo solo. Revista Brasileira de Agrociência, Pelotas, v.11, p. 101-103, 2005. Nota técnica
OLIVEIRA, A.L.M.; URQUIAGA, S.; DÖBEREINER, J.; BALDANI, J.I. The effect of inoculating endophytic $\mathrm{N}_{2}$-fixing bacteria on micropropagated sugarcane plants. Plant and Soil, Crawley, v.242, p.205-215, 2002.

OLIVEIRA, A. M. G.; SOUZA, L. F. S. S.; RAIJ, B. V.; MAGALHÃES, A. F. J.; BERNARDI, A.C.C. Nutrição, calagem e adubação do mamoeiro irrigado. Embrapa Circular Técnica, Brasília, v. 69, p.1-5, 2004.

PAULA, M. A.; REIS, V. M.; DÖBEREINER, J. Interations of Glomus clarum with A. dizotrophicus in infection of sweet potato, sugar cane, sweet sorghum. Biology and Fertility of Soils, Berlin, v.11, p. 111-115, 1991.

PAULA, M. A.; URQUAIA. S.; SIQUEIRAS, J. O., DÖBEREINER, J. Synergitic effects of vesiculararbuscular mycorrhizal fungi and diazotrophic bacterias on nutrition and grown of sweet potato. Biology and Fertility of Soils, Berlin, v.14, p. 6166, 1992.

RAIMAM, M. P.; ALBINO, U.; CRUZ, M. F.; LOVATO, G. M.; SPAGO, F.; FERRACIN, T. P.; LIMA D. S.; GOULART, T.; BERNARDI, C. M.; MIYAUCHI, M.; NOGUEIRA, M. A.; ANDRADE, G. Interaction among free-living $\mathrm{N}$-fixing bacteria isolated from Drosera villosa var. villosa and AM fungi (Glomus clarum) in rice (Oryza sativa). Applied Soil Ecology, Amsterdam, v. 35, p. 25-34, 2007.

SALA, V. M. R.; FREITAS, S. S.; SILVEIRA, A. P. D. Interação de fungos micorrízicos arbusculares e bactérias diazotróficas em trigo. Pesquisa Agropecuária Brasileira, Brasília, v.42, p. 1593-1600, 2007.

SANTOS, S.T. dos. Biogeografia de bactérias culturáveis associadas a fruteiras tropicais. 2008. 92 f. Tese (Doutorado em Biociências e Biotecnologia) - Universidade Estadual do Norte Fluminense, Campos dos Goytacazes, 2008.

SILVA, M. A. da, CAVALCANTE, U.W.T.; SILVA, F.S.B. da, SOARES, A.A.G.; MAIA, F.S.B. Crescimento de mudas de maracujazeiro-doce (Passiflora alata Curtis) associadas a fungos micorrízicos arbusculares (Glomeromycota). Acta Botanica Brasílica, São Paulo, v.18, p. 981-985, 2004. 
SILVEIRA, A. P. D.; SILVA, L. R. S; AZEVEDO, I. C., OLIVEIRA, E. O.; MELETTI, L. M. M. Desempenho de fungos micorrízicos arbusculares na produção de mudas de maracujazeiro-amarelo, em diferentes substratos. Bragantia, Campinas, v.62, p. 89-99, 2003.

SOUZA, L. F. S.; TRINDADE, A. V.; OLIVEIRA, A. M. G. Calagem, exigências nutricionais e adubação. In: TRINDADE, A.V. Mamão. Produção: aspectos técnicos. Brasília: Embrapa Comunicação para Transferência de Tecnologia, 2000. p. 26-34.

TOLJANDER J. F.; ARTURSSON, V.; PAUL, L. R.; JANSSON, J. K.; FINLAY, R. D. Attachment of different soil bacteria to arbuscular mycorrhizal fungi is determined by hyphal vitality and fungal species. FEMS Microbiology Letters, Amsterdam, v. 254, p. 34-40, 2006.
TRINDADE, A. V.; DANTAS, J. L. L.; ALMEIDA, F.P.; MAIA, I. C. S. Estimativa do coeficiente de determinação genotípica em mamoeiros (Carica papaya L.) inoculados com fungo micorrízico arbuscular. Revista Brasileira de Fruticultura, Jaboticabal, v. 23, p. 607-612, 2001a.

TRINDADE, A. V.; FARIA, N. G.; ALMEIDA, F. P. Uso de esterco no desenvolvimento de mudas de mamoeiro colonizados com fungos micorrízicos. Pesquisa Agropecuária Brasileira, Brasília, v.35, p.1389-1394, 2000.

TRINDADE, A. V.; SIQUEIRA, J. O.; ALMEIDA, F. P. Dependência micorrízica de variedades comerciais de mamoeiro. Pesquisa Agropecuária Brasileira, Brasília, v. 36, n. 12, p. 1485-1494, 2001 b.

TRINDADE, A.V; SALQUEIRO, J. L. L. ; SANTOS, T. M. C. DOS. Crescimento e produtividade do mamoeiro a partir de mudas micorrizadas, sob diferentes esquemas de adubação. In: PAPAYA BRASIL: QUALIDADE DO MAMÃO PARA O MERCADO INTERNO, 1., 2003, Vitória. Resumos... Vitória: INCAPER, 2003. 728p. 